\title{
ELECTROMAGNETIC SYSTEM ANALYSIS AND IMPROVEMENT OF A NOVEL 3-DOF DEFLECTION TYPE PERMANENT MAGNET MOTOR
}

\author{
Zheng Li, Ruodong Zhi, Qunjing Wang
}

Original scientific paper

This paper presents the electromagnetic analysis of a novel fluid damping based hybrid drive multi-degrees-of-freedom permanent magnet motor based on analytical and 3D finite element methods. The spatial magnetic field calculation model, torque analysis model, oil film model and electromagnetic-thermal coupling are presented and developed. Based on the simulation calculation results, some important features on the magnetic field and torque characteristics, oil film and electromagnetic-thermal coupling are derived and their effects are discussed in detail with some further improvement design possibilities. The results provide the primary theoretical guide for the configuration design, optimization and control research of three degrees of freedom deflection type actuators.

Keywords: analytical method; electromagnetic-thermal coupling; magnetic field; multi-DOF; oil film; torque

Analiza elektromagnetskog sustava i poboljšanje novog 3-DOF motora s permanentnim magnetom s otklonom

Izvorni znanstveni članak

Ovaj rad predstavlja elektromagnetsku analizu novog motora s permanentnim magnetom na hibridni pogon s više stupnjeva slobode zasnovan na analitičkoj i 3D metodi konačnih elemenata. Prezentirani su i razvijeni proračunski model prostornog magnetskog polja, model analize zakretnog momenta, model uljnog sloja i elektromagnetsko-toplinske spojke. Na temelju simulacijskih rezultata proračuna, nekih važnih značajki karakteristika magnetskog polja i zakretnog momenta, izvedeni su uljni sloj i elektromagnetsko-toplinska spojka i detaljno proanalizirani njihovi učinci s nekim daljnjim mogućnostima poboljšanja oblikovanja. Rezultati pružaju primarni teorijski vodič za dizajn konfiguracije, optimizaciju i istraživanje reguliranja aktuatora deflekcijskog tipa s tri stupnja slobode.

Ključne riječi: analitička metoda; elektromagnetsko-toplinska spojka; magnetsko polje; multi-DOF; uljni film; zakretni moment

\section{Introduction}

With the rapid development of modern industry and technology, the applications of manipulators and actuators which can achieve three-degree-of-freedom (3-DOF) motions with energy conversion process are used more and more widely. This kind of execution and energy conversion devices are usually built with multiple conventional motors or actuators, each having one degreeof-freedom, which leads to reducing the position accuracy, efficient, dynamic performance of the system. In this respect, the multi-DOF actuators or motors have attracted much attention [1-5]. However, their operation mechanisms and control algorithms are obviously different from those used for single-DOF actuator or motor's control system, also the design and optimization scheme are not suitable for the multi-DOF actuator applications [6, 7]. In this paper, based on our initial deflection type 3-DOF motor design, a new type of fluid damping based hybrid drive multi-DOF PM motor is introduced, with the electromagnetic system analysis and fluid dynamics calculation are introduced in detail. The increasing requirements of operation speed and accuracy with low friction and resistance, make it necessary to further reduce the machining error caused by bearing support structure and thermal deformation for its spacial movement. So it is important to establish an accurate calculation method of the presented motor with fluid suspension mode to analyze its characteristics.

Based on the principle of fluid damping based hybrid drive multi-DOF PM motor, the research background is firstly presented; then the magnetic field and torque analysis methodology are accomplished; finally, the oil film and electromagnetic-thermal coupling analysis is carried out to derive the results, which makes a primary investigation on the design and optimization of the motor.

\section{Operation principle and structure of PM multi-DOF motor}

The description of the mechanism of the motor is given in detail. The schematic diagram is shown in Fig. 1. As can be seen, when the coils, named 2 and 5', are loaded with direct current, it will generate magnetic pole called $\mathrm{N}$ pole, and the 2' and 5 coil loaded with current will produce magnetic pole called $\mathrm{S}$ pole. The magnetic poles of the same polarity generate the mutually exclusive forces; the poles of the opposite polarity generate attractive forces, which can derive the synthesized electromagnetic torque making the rotor complete the deflection movement around the $X$-axis.

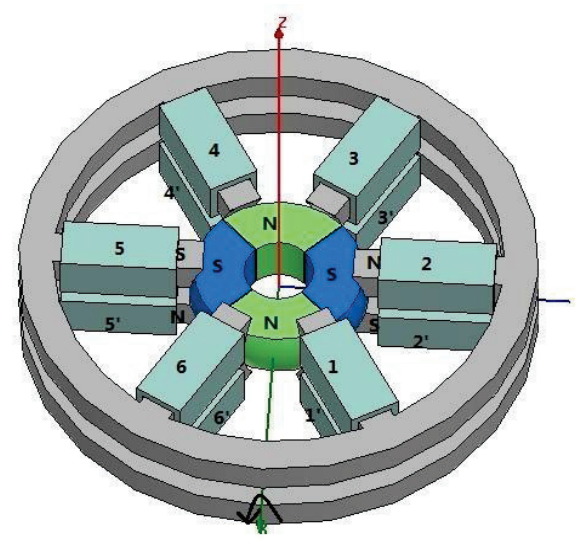

Figure 1 Structure of the motor

Activating the 3, 4, 1' and 6' coils with direct current can produce magnetic pole called S pole; the 3', 4', 1 and 
6 coils with direct current can produce magnetic pole called $\mathrm{N}$ pole. Thus the synthetic electromagnetic torque can make the motor complete the deflection movement around the Y-axis. Based on the similar method that energizes the coils in different directions, the synthetic tangential electromagnetic torques can make the actuator accomplish the rotational movement around the $Z$-axis.
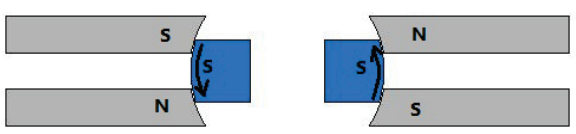

Figure 2 The deflection type motion around the $X$ axis

Based on the motor model in the previous studies [8-10], some improvements and innovations are considered and performed on the model, aiming to solve the problems of friction loss, low precision and difficulty in control of permanent magnet motors. A new type of fluid damping based hybrid drive multi-DOF PM motor is mainly proposed.

The working principle of the motor is based on the interaction between a magnetic field generated by the energized coil and the permanent magnet field. Motor is mainly constituted by stator spherical shell, rotor spherical shell and output shaft, as shown in Fig. 3. The outside of stator spherical shell is inlaid with magnet winding coil. The liquid oil film is filled between the stator shell and the rotor shell, which is designed to reduce the friction between the stator and the rotor and adjust the damping of the rotor movement. The largescale movement of the motor is completed by the permanent magnet of the vertical position, while the accurate fine tuning is realized by the permanent magnet located at the end.

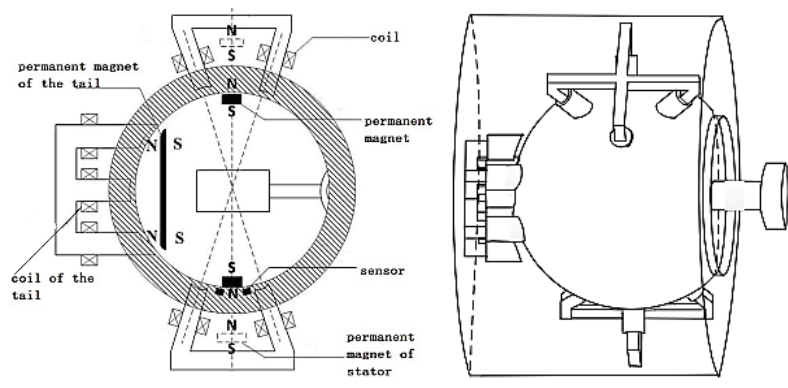

Figure 3 Structure of the motor

\section{Analysis and simulation}

\subsection{Principle of the magnetic field and torque}

With the increasing complexity of the motor structure and the development of simulation technology, in order to obtain more accurate results, the finite element method (FEM) is widely used in the analysis of the electromagnetic characteristics of the motor. With the special structure of stator and rotor, the fluid damping based hybrid drive multi-degrees-of-freedom PM motor has a complex magnetic field and torque. In this work, the finite element analysis software is used to calculate the magnetic field and torque of the motor. The magnetic induction intensity $B$ is chosen as the solution function.
Under the condition of steady magnetic field, the Maxwell equation:

$$
\left\{\begin{array}{c}
\nabla \times H(x, y, z)=J(x, y, z) \\
\nabla \cdot B(x, y, z)=0
\end{array}\right.
$$

where $H(x, y, z)$ is magnetic field intensity; $J(x, y, z)$ is current density vector; $B(x, y, z)$ is magnetic induction intensity. These three components are direction vector functions in the coordinate system, where magnetic induction intensity can be expressed as:

$$
B(x, y, z)=B_{x} \cdot \vec{x}+B_{y} \cdot \vec{y}+B_{z} \cdot \vec{z}
$$

In order to obtain three components of the air-gap flux density in the spherical coordinate system, this work applies the principle of coordinate transformation. According to the relationship of each component in rectangular coordinate and spherical coordinate, the magnetic flux density in the spherical coordinate is expressed as follows:

$$
\begin{aligned}
& B_{1 r}=\left[B_{x} \cos (\varphi)+B_{y} \sin (\varphi)\right] \sin (\theta)+B_{z} \cos (\theta) \\
& B_{1 \theta}=\left[B_{x} \cos (\varphi)+B_{y} \sin (\varphi)\right] \cos (\theta)-B_{z} \sin (\theta) \\
& B_{1 \varphi}=-B_{x} \sin (\varphi)+B_{y} \cos (\varphi)
\end{aligned}
$$

where $r, \theta, \varphi$ are the three components of the air-gap flux density in the spherical coordinate system.

The torque characteristic is an important performance index for the stability of the motor [11, 12]. The virtual displacement method is used to calculate the motor torque. It is assumed that the linkage is constant after virtual displacement, then the system is a lossless energy storage system. The total energy storage in solution domain is:

$W=\int_{V} \int_{0}^{B} H \cdot \mathrm{d} B \mathrm{~d} V$

where $V$ is field volume; $H$ is magnetic field intensity; for isotropic linear medium, $B=\mu H$.

According to the virtual displacement method, it is assumed that the rotor has a very small angular displacement $\varphi^{\prime \prime}$ along the equatorial line direction, and a very small angular displacement $\theta^{\prime \prime}$ along any longitude direction, so the rotor torque under the direction $\varphi^{\prime \prime}$ and $\theta^{\prime \prime}$ is:

$$
\begin{aligned}
& T_{\varphi}=-\partial W / \partial \varphi \\
& T_{\theta}=-\partial W / \partial \theta
\end{aligned}
$$

where $T_{\varphi}$ is the rotational torque component along the equatorial line; $T_{\theta}$ is the component of the deflection torque along any longitude line. The synthetic torque makes the motor to perform fine tuned motion. 


\subsection{Magnetic field analysis}

The permanent magnetization $M_{0}=\left(\begin{array}{c}M_{0, r} \\ M_{0, \theta} \\ M_{0, \varphi}\end{array}\right)$, and the three components are

$$
\begin{aligned}
& M_{0 r}=(-1)^{p-1} M_{0} \cos \left[\varphi-\alpha_{0}-\frac{2 \pi}{P}(p-1)\right] \sin \theta \\
& M_{0 \theta}=(-1)^{p-1} M_{0} \cos \left[\varphi-\alpha_{0}-\frac{2 \pi}{P}(p-1)\right] \cos \theta \\
& M_{0 \varphi}=(-1)^{p} M_{0} \sin \left[\varphi-\alpha_{0}-\frac{2 \pi}{P}(p-1)\right]
\end{aligned}
$$

where $p=1,2, \ldots, P, P$ is the total number of magnetic poles, and $\frac{\pi}{4}(p-1)+\alpha_{0}-\frac{\alpha}{2}<\varphi<\frac{\pi}{4}(p-1)+\alpha_{0}+\frac{\alpha}{2}$, $\frac{\pi}{2}-\frac{\beta}{2}<\theta<\frac{\pi}{2}+\frac{\beta}{2}$. Due to the non-existence of values of $M_{0 \theta}$ and $M_{0 \varphi}, M_{0 r}$ can be expanded with the spherical harmonic functions:

$$
M_{0 r}^{S}(\theta, \varphi)=\sum_{n=0}^{\infty} \sum_{m=n}^{n} C_{n m} Y_{n}^{m}(\theta, \varphi)
$$

where

$$
\begin{aligned}
& C_{n m}=M_{0} \int_{0}^{2 \pi} f(\varphi) \mathrm{e}^{-i m \varphi} \mathrm{d} \varphi \int_{0}^{\pi} S_{n}^{m}\left[P_{n}^{m}(\cos \theta)\right] \sin ^{2} \theta \mathrm{d} \theta \quad \text { and } \\
& f(\varphi)=(-1)^{p-1} \cos \left[\varphi-\alpha_{0}-\frac{\pi}{4}(p-1)\right], p=1,2, \ldots, 8 . \\
& \text { Set } \quad a_{m} \pm b_{m} i=\int_{0}^{2 \pi} f(\varphi) \mathrm{e}^{-i m \varphi} \mathrm{d} \varphi,
\end{aligned}
$$

$C_{m, n}=\int_{0}^{\pi} S_{n}^{m}\left[P_{n}^{m}(\cos \theta)\right] \sin ^{2} \theta \mathrm{d} \theta,\left|a_{m}+b_{m} i\right|$ and $c_{m, n}$ are the radial component of permanent magnetization that indicates the distribution features of magnetic field.

From Fig. 4 and 5, it can be derived that when $m=$ $\pm 2, n=2, c_{n m} \neq 0$, the scalar magnetic potential can be expressed as

$$
\Phi_{1}=B_{2}^{-2} r^{-3} Y_{2}^{-2}+B_{2}^{2} r^{-3} Y_{2}^{2}
$$

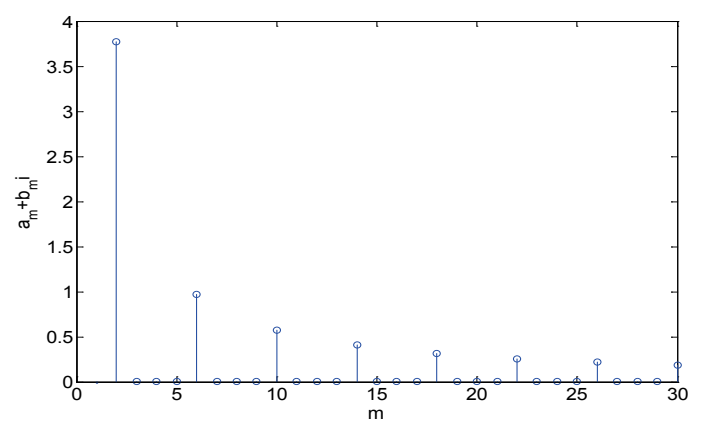

Figure 4 The variation of $\left|a_{m}+b_{m i}\right|$ and $m$

Fig. 6 presents the change of outer air gap magnetic density radial component $B_{1, r}$ with respect to the $\varphi$ and $\theta$. Since the spin rotation angle of the rotor is limited to $0^{\circ} \div$ $360^{\circ}$, the deflection angle is limited to $\pm 33^{\circ}$, the $\varphi$ and $\theta$ are considered to the range of $\left(0^{\circ}, 360^{\circ}\right)$ and $\left(60^{\circ}, 120^{\circ}\right)$ in the analysis of the radial component of air-gap magnetic density.

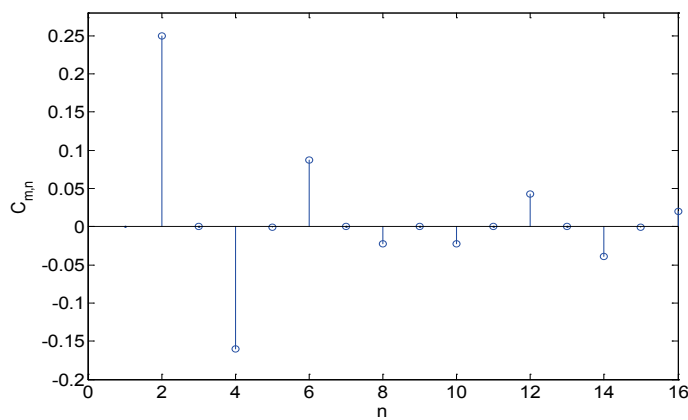

Figure 5 Variation of $C_{m, n}$ and $n$

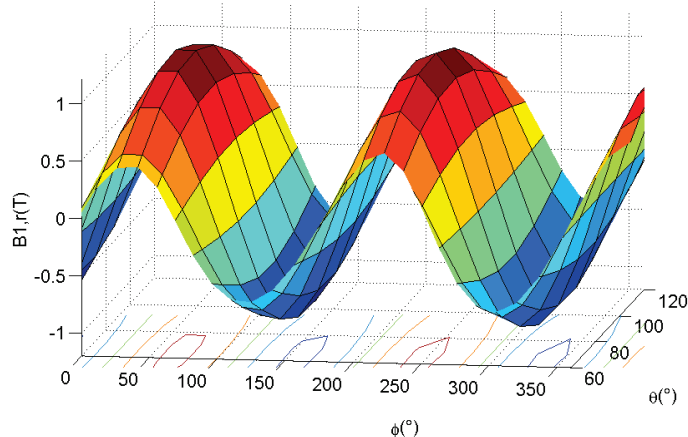

Figure $6 B_{1, r}$ distribution of the drum type rotor

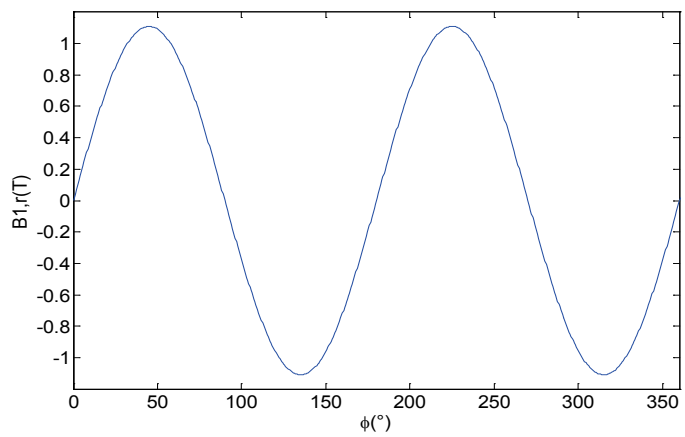

Figure 7 Changes of $B_{1, r}$ with $\varphi$

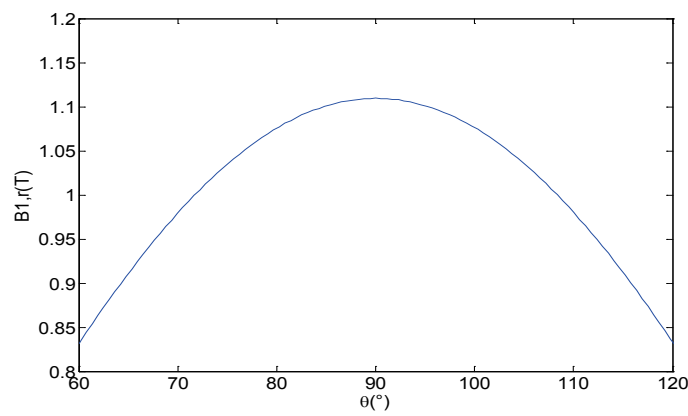

Figure 8 Changes of $B_{1, r}$ with $\theta$

It can be seen from Fig. 6 that the flux density in the $\varphi$ and $\theta$ directions changes with cosine wave forms. The value along the rotor's equator has two peaks and two troughs in whole period, which is just in accordance with the four-pole alternately arranged rotor structure. Fig. 7 and 8 give the changes of $B_{1, r}$ with respect to $\varphi$ and $\theta$. It can be seen from Fig. 7, the air gap magnetic field density curve has 2 positive summits and 2 negative summits 
along the equator, and the extreme points are $\varphi=k \pi / 2,(k$ $=0,1,2,3)$, due to the rotor's alternative turns by $\mathrm{N}$ and $\mathrm{S}$ poles. From Fig. 8, the air-gap magnetic field density changes with sine wave forms along $\theta$ direction. In the angle range $60^{\circ} \div 120^{\circ}$, the maximum value appears at $\theta$ $=90^{\circ}$, i.e. the equatorial positions.

\subsection{Simulation of ending air-gap magnetic field and ending torque}

The coils at the end part and the permanent magnet of the motor are shown in Fig. 9. In this work, the permanent magnet is magnetized by the way of the radial magnetization, and the simulation analysis of the permanent magnet is carried out. The magnetic density vector distribution with radial magnetization is shown in Fig. 10. Due to the coil distribution being along radius direction of the permanent magnet, the radial magnetizing method is applied to make the motor permanent magnet and coil have a better fit, which will generate stable torque.

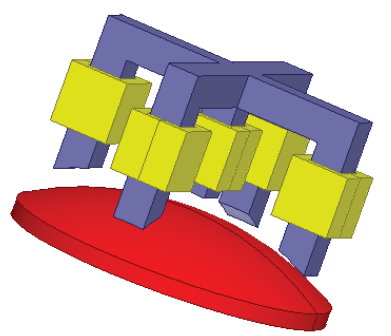

Figure 9 The ending structure of the motor

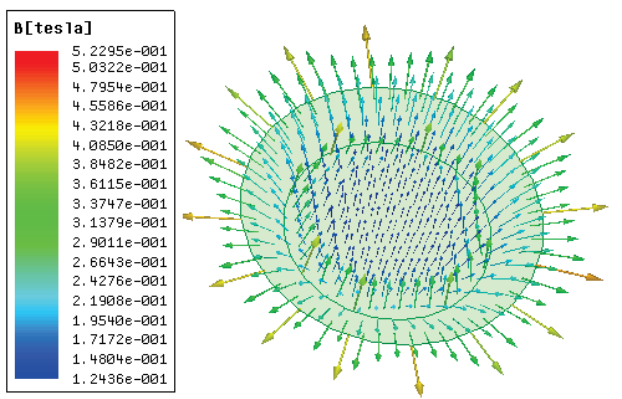

Figure 10 Radial magnetization of ending permanent magnet

The electromagnetic force which causes the torque of the electromagnetic spherical actuator with three-degreeof-freedom is determined by the position of the permanent magnet rotor in the actuator and the current inputs of the coils [13]. In order to analyze the relationship between the torque and motor coils, the Ansoft software is used to analyze the characteristics of the motor's fine adjusting torque at the end part. The deflection of the ending permanent magnet around the $\mathrm{X}$ axis is shown as Fig. 11 . The ending coils are given $300 \mathrm{~A}$ with DC current, as can be seen, the torque of initial position is $0.5 \mathrm{~N} \cdot \mathrm{m}$; when the deflection angle is $5^{\circ}$, the maximum deflection torque is $0.52 \mathrm{~N} \cdot \mathrm{m}$, the torque will decrease if it continues to move; the torque is reduced to $0.32 \mathrm{~N} \cdot \mathrm{m}$, when the angle is $20^{\circ}$. On the basis of large deflection, the main function of the ending permanent magnet is to complete the torque. The simulation results show that the deflection torque can meet the requirement of precise adjustment.

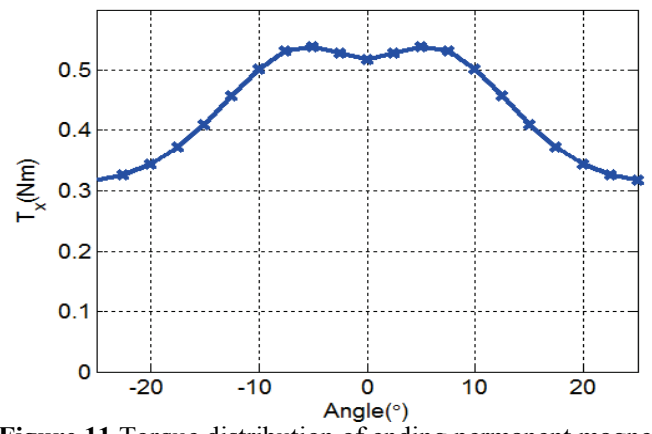

Figure 11 Torque distribution of ending permanent magnet

The cause of the torque is the interaction between the air-gap magnetic field generated by the permanent magnet of the motor and the magnetic field generated by the stator charged coils, so it is very important to analyze the air-gap magnetic field distribution of permanent magnet. The spatial distribution of air-gap flux density in the spherical coordinate system is shown in the following Fig. 12. It can be seen from the chart, there is a single permanent magnet, because of the impact of harmonics, the motor air-gap magnetic flux density, which is along the radial component, distributes as sine wave in the $\theta$ direction, and there are three obvious peaks in the picture; the air-gap flux density reaches the peak when $\phi=60^{\circ}$, which is gradually decreased to the ends. The tangential component of magnetic field strength is continuous in the boundary of rotor and core.

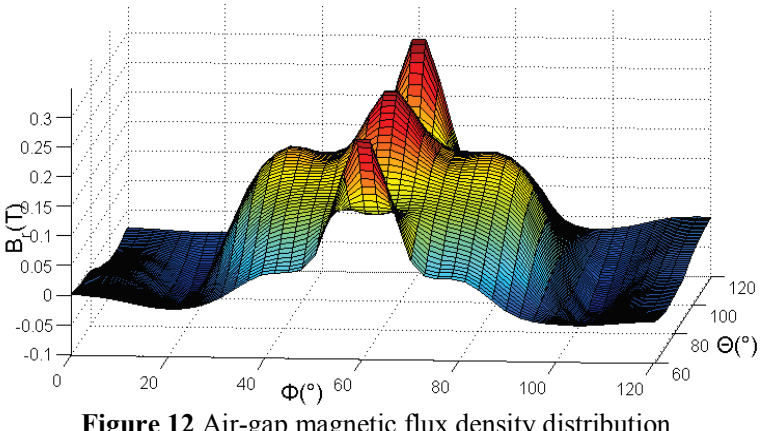

Figure 12 Air-gap magnetic flux density distribution

\subsection{Simulation of air-gap magnetic field and torque}

The schematic diagram of the finite element model of the permanent magnet rotor is shown in Fig. 13 based on the fluid damping based hybrid drive multi-DOF PM motor. The radius of the inside sphere is $40 \mathrm{~mm}$, the radius of outer sphere is $50 \mathrm{~mm}$, the maximum height of the permanent magnet rotor is $40 \mathrm{~mm}$, the pole pairs is 2 , that is there are 4 poles. The $\mathrm{N}$ pole $\mathrm{S}$ pole is arranged alternately. The air-gap between the $\mathrm{N}$ pole and $\mathrm{S}$ pole of the permanent magnet is $0.2 \mathrm{~mm}$.

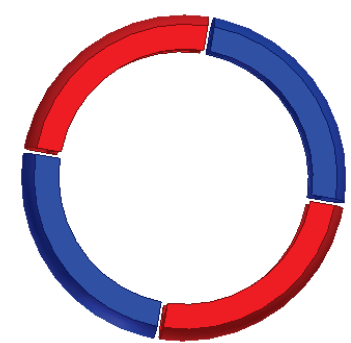

Figure 13 The diagram of Large-scale permanent magnet 
The permanent magnet with linear demagnetization effect is simulated by the equivalent current sheet on the magnet surface in Ansoft Maxwell. Some permanent magnets have linear demagnetization effect:

$M_{p}=\mu_{r} \times H_{c}$

where $M_{p}$ is the intensity of permanent magnet magnetization; $\mu_{r}$ is the relative permeability of permanent magnet; $H_{c}$ is coercive force of permanent magnet.

$$
B_{r}=\mu_{0} \times M_{p}
$$

where $\mu_{0}$ is vacuum permeability; $B_{r}$ is residual magnetic induction.

In the definition of the material, the other two parameters can be calculated using the formula by the given two parameters in 3D finite element software. In recent years, in order to have a good performance, there is increasing trend on selecting $\mathrm{NdFeB}$ as the material of permanent magnet motor, which has a linear demagnetization. So in this work, the material is set with $\mathrm{NdFeB}$, and the definition of coercive force $H_{c}=890$ $\mathrm{KA} / \mathrm{m}$, and the relative permeability $\mu_{r}=1.02$.

The schematic diagram of magnetic flux density of permanent magnet rotor under axial magnetization is shown in Fig. 14. It can be seen that the two $\mathrm{N}$ poles are located at left and right position, the two $\mathrm{S}$ poles are located at the upper and lower position. A circular magnetic field is induced between different polarity permanent magnets.
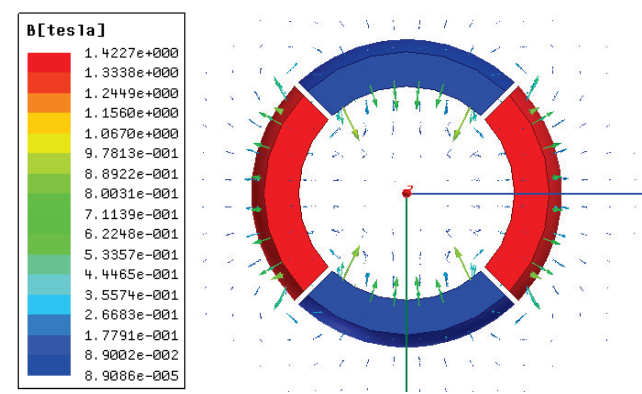

Figure 14 The distribution of axial magnetic flux density vector

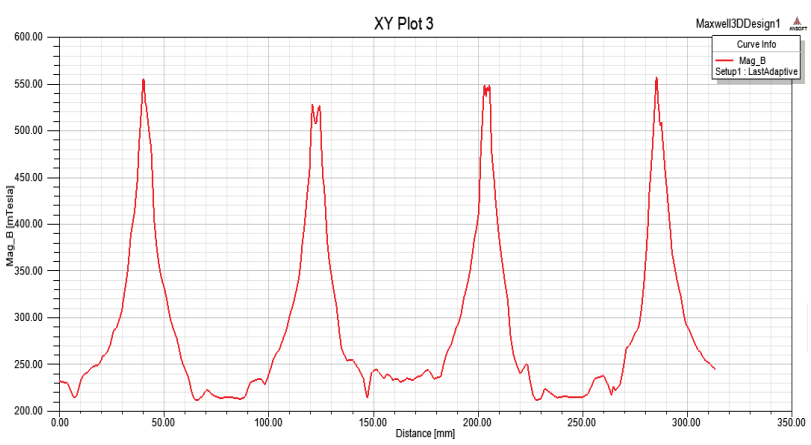

Figure 15 The distribution curve of air-gap flux density with axial magnetization

In order to obtain the optimal solution of a permanent magnet rotor, the variation of the magnetic field induced by the $0.2 \mathrm{~mm}$ gap above the equator is analyzed in this step. Through the comparison of air-gap magnetic field under different conditions, an optimal model of height and thickness is obtained. The air-gap flux density curve of the motor is shown in Fig. 15. It can be seen from Fig. 15 that the maximum magnetic density occurs in the gap of the permanent magnet, and the minimum magnetic density appears in the middle of each permanent magnet.

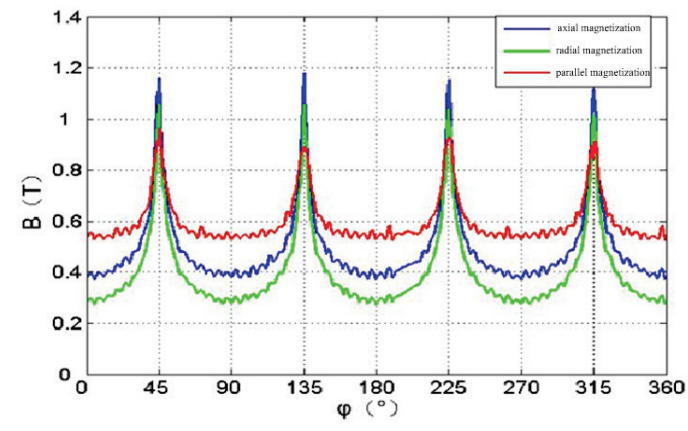

Figure 16 The distribution curve of magnetic density modulus value with $\theta=90^{\circ}$

The magnetic density modulus values with $\theta=90^{\circ}$ are shown in Fig. 16. It can be seen from Fig. 16 that the distribution of magnetic induction intensity appears to be periodically distributed with the $\varphi$ changing. There are also four similar sharp waveform cycles, which is the reason that four permanent magnets are fixed to the position of permanent magnet rotor. It is obvious that the maximum modulus value of magnetic flux density occurs at the junction between the $\mathrm{N}$ pole and the $\mathrm{S}$ pole. In the middle of a single magnet, the minimum modulus value of the magnetic density is found. The reason is that the rotor permanent magnet is composed of $\mathrm{N}$ pole and $\mathrm{S}$ pole, so it generates magnetic circuit exchanges which cause the strongest magnetic flux density to occur in the intersection of $\mathrm{N}$ pole and $\mathrm{S}$ pole, and the weakest magnetic flux density in the midline of permanent magnet.

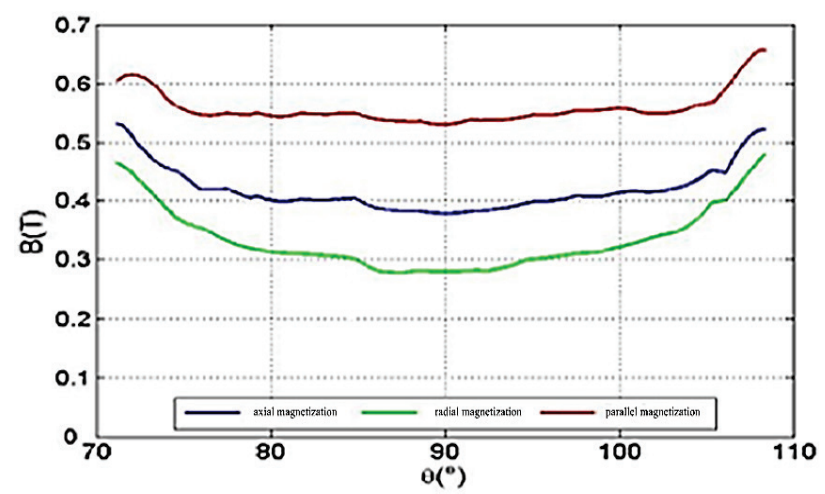

Figure 17 The distribution curve of magnetic density modulus value with $\varphi=0^{\circ}$

By comparing the different waveform curves under the three methods of magnetization, it can be concluded that the maximum modulus value of the magnetic induction intensity appears in the axial magnetizing mode, which is distributed around the magnet junction. Under the condition of axial magnetization, the magnetic induction intensity of the permanent magnet is larger, and the mode of the radial magnetization is relatively smaller, the mode of the parallel magnetization is the smallest. 
This regular pattern only emerges in a specific angle. In most practical view, parallel magnetization is the best choice of the magnetizing methods for magnetic induction intensity, which is more suitable for most of the majority situation.

The distribution of magnetic induction intensity of air-gap magnetic field magnetized with three different modes when the permanent magnet rotor is in spherical coordinates with $\varphi=0^{\circ}$ is shown in Fig. 17. The distance between the air-gap and the edge of the rotor is $0.2 \mathrm{~mm}$. According to the three curves presented in the figure, the three curves are symmetrical, $\theta=90^{\circ}$ is the symmetrical axis. There is a minimum value of magnetic induction intensity when $\theta=90^{\circ}$. On the basis of the three different magnetic induction curves that are magnetized in three different ways, it can be concluded that the value of magnetic induction under the parallel magnetization is maximum, the value of magnetic induction intensity under the axial magnetization is relatively small, and the value of magnetic induction intensity under the radial magnetization is the smallest.

Compared with different magnetizing modes, the parallel magnetization method has strong advantages on the simulation, so the parallel magnetization method is selected as the way to simulate. The air-gap magnetic flux density of three-dimensional curve is shown in the following Fig. 18.

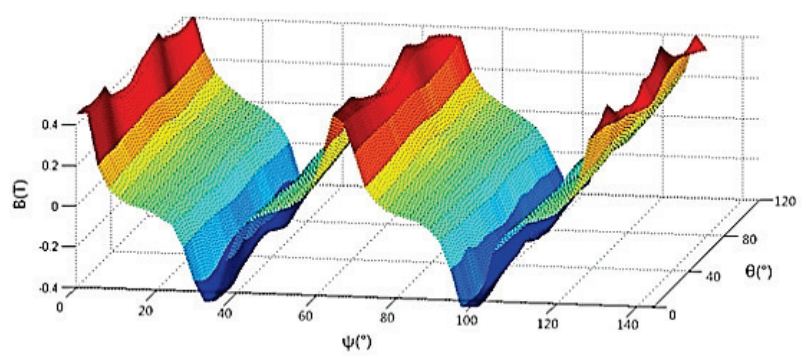

Figure 18 The three dimensional distribution of air-gap flux density

\subsection{Simulation of the oil film}

The rotor is affected by the pressure and resistance of the oil film, which is sealed between the stator and the rotor to adjust the damping of the rotor movement, when the motor is running. Besides, the motor speed and eccentric motion will also have a certain impact on the oil film which may affect the operation stability of the motor. It is necessary to analyze the oil film pressure and resistance. The pressure distribution of the liquid film is shown in the following figure under the condition that the speed of the rotor is $360 \mathrm{rpm}$ without eccentricity. It can be seen from Fig. 19, the oil film pressure distribution is not uniform, where the largest value $1765 \mathrm{~Pa}$ appears in the middle of the spherical surface while the pressure decreases from middle to two sides, and the negative pressure appears in the two poles of the spherical surface. So it is important to increase the strength of the stator shell and rotor shell, especially at the center and the poles, when making motor optimization design.
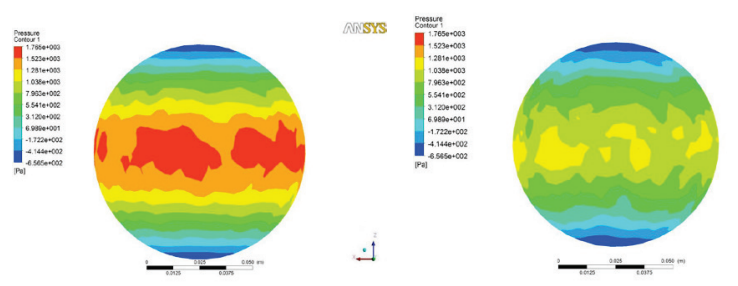

Figure 19 Pressure distribution of stator and rotor surface

In order to study the effect of motor speed on the pressure distribution of oil film, the pressure distribution of oil film is obtained at different speeds. The pressure distribution is shown in Fig. 20 when the speed is 300 $\mathrm{rpm}, 420 \mathrm{rpm}$ and $540 \mathrm{rpm}$ respectively. The oil film pressure distribution of stator surface is shown in the left picture, and the pressure distribution of rotor surface on the other side. Under the condition of the three speeds, the maximum value of the oil film pressure of the stator surface is $1240 \mathrm{~Pa}, 2231 \mathrm{~Pa}, 3491 \mathrm{~Pa}$, respectively. As can be seen, when the motor is running in stable operation, the distribution of the oil film pressure is uniform which is descending along the latitude direction. With the increasing of the rotor speed the oil film pressure increases, the maximum positive pressure of oil film increases from $300 \mathrm{rpm}$ to $540 \mathrm{rpm}$, which is 3 times the value of original. It is obvious that the speed of the motor has a great influence on the pressure of oil film.
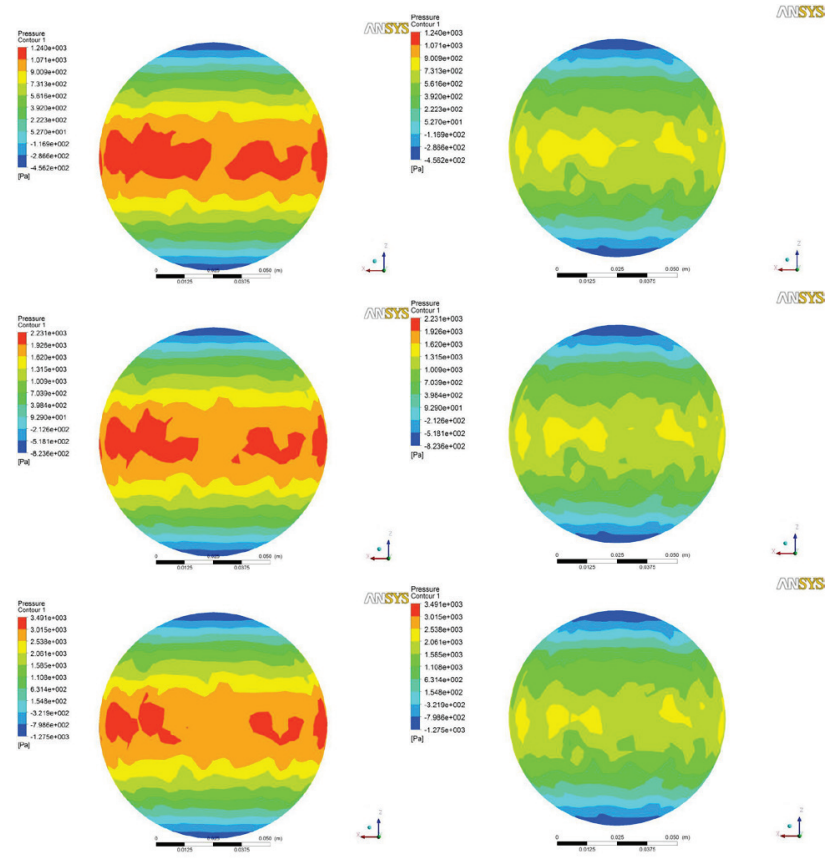

Figure 20 Pressure distribution in different motor speeds

Considering the eccentric motion, the rotor which is suspended in the liquid oil film between the stator and the rotor is subjected to unbalanced pressure. So it is very important to study the distribution of the oil film pressure when the motor is under eccentricity. Fig. 21 shows the oil film pressure distribution of the motor at the speed of $360 \mathrm{rpm}$, eccentricity of $e=0.4$, where the left side is the stator surface, the other side is the rotor surface. As can be seen, compared with stable operation, the maximum pressure is $2156 \mathrm{~Pa}$, which indicates that the eccentric operation can increase the oil film pressure, leads to nonuniform distribution, also makes the negative pressure 
ranges increase. The motor design should consider the influence of eccentric motion.
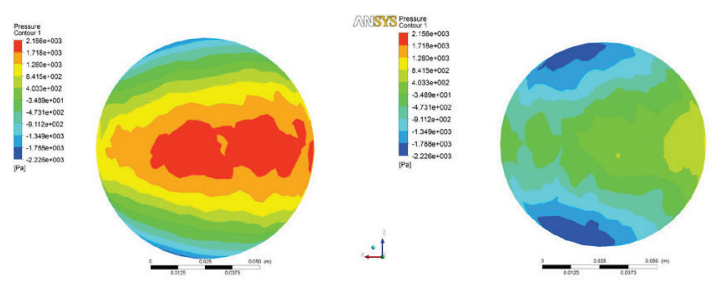

arsis

Figure 21 Pressure distribution with eccentric motion

\subsection{Simulation of electromagnetic-thermal coupling}

Electrodynamical stresses and vibrations can severely damage winding insulations, end bracings and support rings, and the vibrations arise under the influence of the electromagnetic field variations $[14,15]$. So it is neccesary to analysis the electromagnetic-thermal coupling of the motor.

When the ending coils are excited with a loop current, the eddy current loss distribution can be obtained by using FEA software. As shown in Fig. 22, the maximum eddy current loss is appearing mainly around the coils.
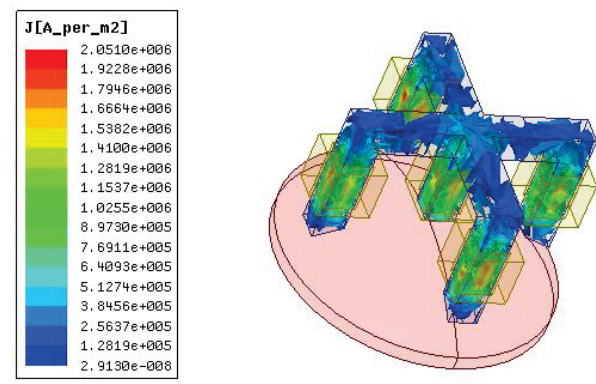

Figure 22 Eddy current loss of coils

In thermal analysis module, eddy current loss is selected as a load, which is imported into the thermal field to complete temperature calculation. The heat flux distribution is shown as Fig. 23, as can be seen, the temperature distribution mainly locates near the coils, which is consistent with the distribution of eddy current loss. It illustrates the correctness of the simulation. The heat flux distribution is shown in Fig. 24, as can be seen, the distribution is uniform and the maximum value is reached $14615 \mathrm{w} / \mathrm{m}^{2}$

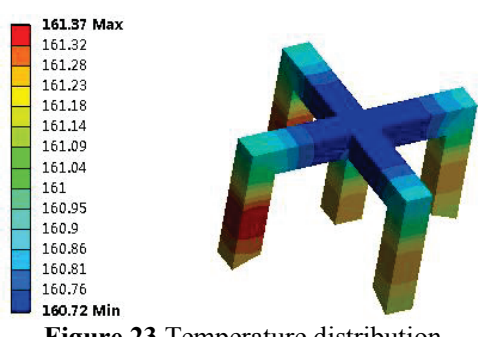

In the next step, the temperature is introduced into the structure analysis module as a load. The upper surface and the fulcrum are selected as the boundary conditions. The following Fig. 25 and 26 show the total deformation and equivalent stress of the coils. It can be seen from the data that the total deformation is mainly located at the fixed coil position of the bracket, the maximum deformation value is $4.0703 \times 10^{-5} \mathrm{~m}$, the value is very small which has little impact on the motor bracket. In Fig. 13 , the maximum value of equivalent stress distribution reaches $1.0591 \times 10^{9} \mathrm{~Pa}$, which is mainly distributed at the inflection point of the bracket. It can be concluded that the strength of the bracket should be considered in the optimization design of the motor.

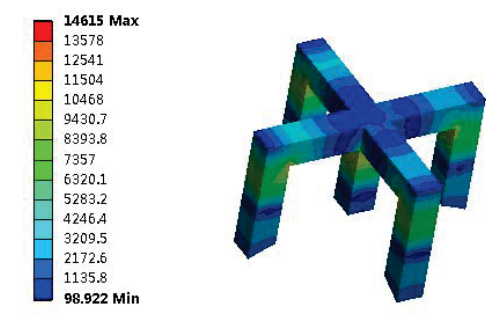

Figure 24 Heat flux distribution

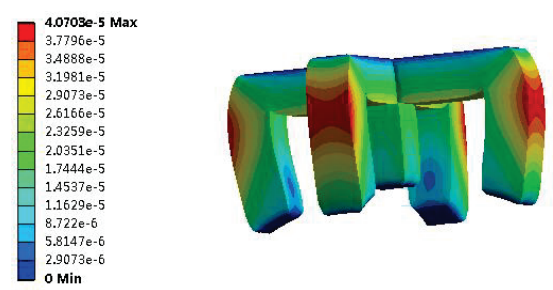

Figure 25 Total deformation

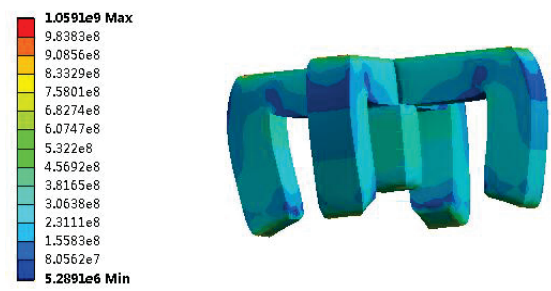

Figure 26 Equivalent stress distribution

\section{Conclusion}

Based on the special structure of the new type fluid damping based hybrid drive multi-degrees-of-freedom PM motor proposed in this work, the electromagnetic calculation and torque analysis are investigated with the three-dimensional finite element method. Besides, the oil film pressure and electromagnetic-thermal coupling analysis is conducted. The results show that the electromagnetic-thermal coupling and the analysis of the motor oil film are beneficial to the reduction of the motor loss, and it provides data and theory for the optimization design.

\section{Acknowledgements}

This work is supported by the National Natural Science Foundation of China (No. 51577048, 51637001, 51107031), the Natural Science Foundation of Hebei Province of China (No. E2014208134), the Overseas Students Science and Technology Activities Funding Project of Hebei Province (No. C2015003044), the Hebei Industrial Technology Research Institute of Additive Manufacturing (Hebei University of Science and Technology) open projects funding, the National Engineering Laboratory of Energy-saving Motor \& Control Technique, Anhui University (No. KFKT201601). 


\section{$5 \quad$ References}

[1] Chirikjian, G. S.; Stein, D. Kinematic design and commutation of a spherical stepper motor. // IEEE Trans. on Mechatronics, 4, 4(1999), pp. 342-353. https://doi.org/10.1109/3516.809513

[2] Stein, D.; Chirikjian, G. S. Experiments in the Commutation and Motion Planning of a Spherical Stepper Motor. // ASME Design Engineering Technical Conferences and Computers and Information in Engineering Conference, Baltimore / Maryland, 2000, pp. $1-7$.

[3] Davey, K.; Vachtsevanos G.; Powers, R. The analysis of fields and torques in spherical induction motors. // IEEE Trans. on Magn. 23, 1(1987), pp. 273-282. https://doi.org/10.1109/TMAG.1987.1064749

[4] Raye, A.; Kok-Meng, Lee. Finite Element Torque Modeling for the Design of a Spherical Motor. // In Proc. the $7^{\text {th }}$ Int. Conf. on Control, Automation and Robotics and Vision, / Singapore, 2002, pp. 390-395.

[5] Wang, J.; Jewell, G. W.; Howe, D. Analysis, design and control of a novel spherical permanent-magnet actuator. // IEE Proc. Electric Power Applications. 145, 1(1998), pp. 61-71. https://doi.org/10.1049/ip-epa:19981635

[6] Dehez, B.; Galary, G.; Grenier, D.; Raucent, B. Development of a Spherical Induction Motor with Two Degrees of Freedom. // IEEE Trans. on Magnetics, 42, 8(2006), pp. 2077-2089. https://doi.org/10.1109/TMAG.2006.876473

[7] Wang, Qunjing; Li, Zheng; Xia, Kun; Ni, Youyuan. Calculation and Analysis on Configuration Parameters and Torque Characteristics of a Novel Spherical Stepper Motor. // Proceedings of the CSEE, 26, 10(2006), pp. 58-165.

[8] Li, Zheng; Lun, Qingqing; Xing, Dianhui; Gao, Peifeng. Analysis and Implementation of a Three-Degrees-ofFreedom Deflection Type PM Motor. // IEEE Trans. on Magnetics, 51, 3 (2015), pp. 1-4.

[9] Li, Z.; Wang, Q. Levitation Mechanism and Improvements of 3-DOF Deflection Type PM Actuator. // IEEE Trans. Appl. Supercond., 26, 7(2016), pp. 1-5. https://doi.org/10.1109/TASC.2016.2610720

[10] Kim, H. Y.; Kim, H.; Gweon, D. G.; Jeong, J. Development of a Novel Spherical Actuator with Two Degrees of Freedom. // IEEE/ASME Transac-tions on Mechatronics, 22, 2(2015), pp. 532-540. https://doi.org/10.1109/TMECH.2014.2308417

[11] Xia, C. L.; Li, H. F.; Shi, T. N. 3D Magnetic Field and Torque Analysis of a Novel Halbach Array Permanentmagnet Spherical Motor. // IEEE Trans. on Magnetics, 44, 8 (2009), pp. 2016-2020. https://doi.org/10.1109/TMAG.2008.922782

[12] Wang, Q. J.; Li, Z.; Xia, K. et al. Calculation and Analysis on Configuration Parameters and Torque Characteristics of a Novel Spherical Stepper Motor. // Proceedings of the CSEE, 26, 10 (2006) pp. 158-165.

[13] Zheng, Li; Yongtao, Wang. Finite Element Analysis and Structural Optimization of a Permanent Magnet Spherical Actuator. // Electronics and Electrical Engineering, 114, 8(2011), pp. 67-72.

[14] Albanese, R.; Calvano, F.; Mut, G. D. et al. Coupled Three Dimensional Numerical Calculation of Force and Stresses on the end Windings of Large Turbo Generators Via Integral Formulation. // IEEE Trans. on Magnetics 48, 2, (2012), pp. 875-878 https://doi.org/10.1109/TMAG.2011.2173307

[15] Stancheva, R. D.; Iatcheva, I. I. 3-D Electromagnetic Force Distribution in the End Region of Turbogenerator. // IEEE Trans. on Magnetics, 45, 3 (2009), pp. 1000-1003. https://doi.org/10.1109/TMAG.2009.2012540

\section{Authors' addresses}

Zheng Li, PhD, Prof.

Hebei University of Science and Technology

School of Electrical Engineering

Shijiazhuang, Hebei 050018, China

E-mail: lzhfgd@163.com

Ruodong Zhi

Hebei University of Science and Technology

School of Electrical Engineering

Shijiazhuang, Hebei 050018, China

E-mail: 271126243@qq.com

Qunjing Wang, PhD, Prof.

Anhui University

National Engineering Laboratory of Energy-saving Motor \&

Control Technique

Hefei, Anhui 230601, China

E-mail: wqunjing@sina.com 